\title{
A CASE STUDY ON POSTERIOR REVERSIBLE ENCEPHALOPATHY SYNDROME WITH ECLAMPSIA
}

\author{
VATHSALYA PORANKI* \\ Department of Pharmacy Practice, A.M Reddy Memorial College of Pharmacy, Guntur, Andhra Pradesh, India. \\ Email: vathsalya17poranki@gmail.com
}

Received: 24 October 2020, Revised and Accepted: 30 November 2020

\begin{abstract}
Posterior reversible neurological disorder syndrome may be a clinical syndrome characterized by varied conditions conferred by the patient need medicine, tomography diagnosing to advocate the treatment. Gestational toxemia of pregnancy toxemia begins throughout the pregnancy because the underlying medical condition of the mother later causes toxemia. These two clinical situations were approached by observatory medical aid depending on the mother's health and nutrition. Here, this case study is of a 37-year-old who conferred in post-pregnancy cesarean with seizures, high pressure, disturbed mental state, and high blood glucose levels. Pregnancy-related clinical syndromes are hugely dependent on the mother's well-being. Syndromes during pregnancy not solely influence the mother's health additionally cause severe hurt to the fetus because leading to rise in premature births, fetal death rate, and inflicting psychological distress to the mother's mental health.
\end{abstract}

Keywords: Eclampsia, Preeclampsia, Toxemia, Pregnancy, High blood pressure, Seizures.

(C) 2021 The Authors. Published by Innovare Academic Sciences Pvt Ltd. This is an open access article under the CC BY license (http://creativecommons.org/ licenses/by/4.0/) DOI: http://dx.doi.org/10.22159/ajpcr.2021v14i1.39920. Journal homepage: https://innovareacademics.in/journals/index.php/ajpcr

\section{INTRODUCTION}

Posterior reversible neurological disorder syndrome (PRES) is related to varied conditions presenting with headache, neurological disorder, seizures, cortical visual disturbances, or visual disorder. This syndrome happens secondary to the shortcoming to the posterior circulation to autoregulate in response to acute changes in blood pressure (BP) [1]. The clinical manifestation is raised perfusion with resultant disruption of the barrier leads to vasogenic lump, sometimes while not pathology, most ordinarily within the parieto-occipital region [2]. High BP during the pre-conceptual stage or after conception results in endothelial dysfunction and vasoconstriction. Hypoperfusion leading to cerebral ischemia and vasogenic edema [3]. Gestational toxemia (preeclampsia) is like a physiological condition of high BP because it additionally involves high pressure at or when 20 weeks of pregnancy in a very woman whose BP was traditional before pregnancy. However, toxemia will embrace BP more than 140/90 mmHg with increased vasogenic edema. Macromolecule within the urine, these conditions lead the explanation for preterm birth (before 37 weeks of pregnancy) if it's severe enough to affect brain performance inflicts seizures or coma it's known as "Eclampsia [4]." Postnatal toxemia of pregnancy describes toxemia of pregnancy that develops during the birth of a child, sometimes between $48 \mathrm{~h}$ and 6 weeks after the birth of the child. Symptoms will embrace raised pressure, severe headache, visual changes, higher abdominal pain, and nausea or instinctive reflex. Postnatal toxemia will occur no matter whether a woman had high BP or toxemia of pregnancy throughout pregnancy [5]. Postnatal toxemia refers to seizures that occur between 48 and $72 \mathrm{~h}$ when delivery. Symptoms additionally embrace high BP and problem respiration. Concerning a third of toxemia cases occur when delivery during which nearly $1 / 2$ those are over $48 \mathrm{~h}$ when the birth [6].

\section{CASE REPORT}

A female patient of age 37 years weighing $60 \mathrm{~kg}$ admitted in hospital with tongue bite, drowsy but arousable, generalized tonic-clonic seizures (GTCS) (7 episodes) in the past 2 days. The patient was moved to the neurology department vitals checked, BP (195/100 $\mathrm{mmHg}$ ), and other vitals were normal. The patient has underactive thyroid for 5 months, hypertensive for 5 years, and diabetic for 6 years. The patient is a $G_{3} P_{1} A_{2} L_{1}-$ had $3\left(G_{3}\right)$ - pregnancies, $1\left(P_{1}\right)$ - preterm infant born after 25 weeks, 2( $\left.\mathrm{A}_{2}\right)$ - pregnancies ended up on spontaneous abortion, and $1\left(\mathrm{~L}_{1}\right)$ - one living child. As for brain imaging, fluidattenuated inversion recovery in magnetic resonance imaging findings is parietal-occipital, vasogenic edema. Pansinusitis (a condition in which paranasal sinuses get inflamed or infected) observed in the left sigmoidal sinus of the patient. Pupils were normal reactive to light. A complete blood picture has resulted as follows: Hemoglobin - $8.7 \mathrm{~g} /$ $\mathrm{dl}$, neutrophils count $-90 \%$ decreased packed cell volume increased mean corpuscular cell volume, and raised erythrocyte sedimentation rate $-48 \mathrm{~mm} / \mathrm{h}$ indicating anemia. The patient was on magnesium sulfate infusion $-4 \mathrm{~g}$. Renal liver function tests were within the range urine analysis revealed proteinuria 2+. A provisional diagnosis for the toxemia is for the first pregnancy, later for the third pregnancy seizures occurred led to eclampsia, seizures GTCS, and lower segment cesarean section -3 months 7 episodes of GTCS before admitting to the hospital. Levetiracetam - 1 g given intravenously to treat seizures thrice a day. For hypertension, amlodipine $-5 \mathrm{mg}$ orally twice a day, for elevated erythrocyte sedimentation rate enoxaparin - $0.4 \mathrm{ml}$ subcutaneously. Supportive therapy was - thiamine intravenously, calcium carbonate, Vitamin $\mathrm{D}_{3}$, and ranitidine are recommended. The patient had facial and peripheral edema spironolactone torsemide was prescribed for the first 4 days. The mother to come to a normal state of being required about 14 days of hospitalization. Neurophysician neurosurgeon was taking over the case during the entire period of patient stay in the hospital. The patient was found to be malnourished during the hospital stay so a proper diet with all required nutritional supplements was suggested by the nutritionist to gain a proper nourished status. Patient and her family were counselled by the gynecologist during inpatient visit regarding the next pregnancy plan suggesting that the pregnancy plan depends upon the patient health status at that time which is considered as primacy of the entire pregnancy plan to safeguard the mother and fetus health.

\section{DISCUSSION}

Planning for pregnancy requires consideration of several factors such as age, underlying medical conditions such as BP and diabetes. In this case, the patient had hypertension for the past 5 years caused toxemia leading to eclampsia affected her health psychologically and physically. Magnesium sulfate was chosen as a choice of treatment to reduce neurological disturbances. 


\section{CONCLUSION}

To understand the confirmed factors causing PRES or eclampsia are under several research studies, even the treatment for these clinical conditions exactly is unknown. However, recordings of such clinical case studies can help us to understand the real-life scenarios of conditions, help to provide better patient care.

\section{ACKNOWLEDGMENT}

I convey my sincere thanks to the patient and her family for being cooperative in providing details of the medical history and background. I also like to thank the neurophysician for helping me to analyze the case and to conduct a case study.

\section{AUTHOR'S CONTRIBUTIONS}

Ms. Vathsalya Poranki was involved in data collection, interviewing the patient, case study, preparation, reviewing, and editing of the manuscript.

\section{CONFLICTS OF INTEREST}

The author declares no conflicts of interest.

\section{AUTHOR'S FUNDING}

Self-sufficient

\section{REFERENCES}

1. Achar SK, Shetty N, Joseph TT. Posterior reversible encephalopathy syndrome at term pregnancy. Indian J Anaesth 2011;55:399-401.

2. American College of Obstetricians and Gynecologists. Hypertension in Pregnancy. Washington, DC: American College of Obstetricians and Gynecologists; 2013.

3. Goldenberg RL, Culhane JF, Iams JD, Romero R. Epidemiology and causes of preterm birth. Lancet 2008;371:75-84.

4. Bigelow CA, Pereira GA, Warmsley A, Cohen J, Getrajdman C, Moshier E, et al. Risk factors for new-onset late postpartum preeclampsia in women without a history of preeclampsia. Am J Obstet Gynecol 2014;210:338.

5. Skurnik G, Hurwitz S, McElrath TF, Tsen LC, Duey S, Saxena AR, et al. Labor therapeutics and BMI as risk factors for postpartum preeclampsia: A case-control study. Pregnancy Hypertens 2017; 10:177-81.

6. Cairns AE, Pealing L, Duffy JM, Roberts N, Tucker KL, Leeson P, et al. Postpartum management of hypertensive disorders of pregnancy: A systematic review. BMJ Open 2017;7:e018696. 